\title{
Higher-Order Sensory Cortex Drives Basolateral Amygdala Activity during the Recall of Remote, but Not Recently Learned Fearful Memories
}

\author{
@Marco Cambiaghi, ${ }^{1}$ Anna Grosso, ${ }^{1}$ Ekaterina Likhtik, ${ }^{2}{ }^{-}$Raffaele Mazziotti, ${ }^{3}$ Giulia Concina, ${ }^{1}$ Annamaria Renna, ${ }^{1}$ \\ Tiziana Sacco, ${ }^{1}$ Joshua A. Gordon, ${ }^{4}$ and $\odot$ Benedetto Sacchetti ${ }^{1,5}$ \\ ${ }^{1}$ Rita Levi-Montalcini Department of Neuroscience, University of Turin, I-10125 Turin, Italy, ${ }^{2}$ Department of Biological Sciences, Hunter College, City \\ University of New York, New York, New York 10065 and Biology Program, Neuroscience Collaborative, Graduate Center, City University of New York, New \\ York, New York 10016, ${ }^{3}$ Institute of Neuroscience, Consiglio Nazionale delle Ricerche, Pisa 56124, Italy, ${ }^{4}$ Department of Psychiatry, College of Physicians \\ and Surgeons, Columbia University, New York, New York 10032, and 5National Institute of Neuroscience-Corso Raffaello 30, I-10125 Turin, Italy
}

Negative experiences are quickly learned and long remembered. Key unresolved issues in the field of emotional memory include identifying the loci and dynamics of memory storage and retrieval. The present study examined neural activity in the higher-order auditory cortex Te2 and basolateral amygdala (BLA) and their crosstalk during the recall of recent and remote fear memories. To this end, we obtained local field potentials and multiunit activity recordings in $\mathrm{Te} 2$ and BLA of rats that underwent recall at $24 \mathrm{~h}$ and $30 \mathrm{~d}$ after the association of an acoustic conditioned (CS, tone) and an aversive unconditioned stimulus (US, electric shock). Here we show that, during the recall of remote auditory threat memories in rats, the activity of the Te 2 and BLA is highly synchronized in the theta frequency range. This functional connectivity stems from memory consolidation processes because it is present during remote, but not recent, memory retrieval. Moreover, the observed increase in synchrony is cue and region specific. A preponderant Te2-to-BLA directionality characterizes this dialogue, and the percentage of time Te2 theta leads the BLA during remote memory recall correlates with a faster latency to freeze to the auditory conditioned stimulus. The blockade of this information transfer via Te2 inhibition with muscimol prevents any retrieval-evoked neuronal activity in the BLA and animals are unable to retrieve remote memories. We conclude that memories stored in higher-order sensory cortices drive BLA activity when distinguishing between learned threatening and neutral stimuli.

Key words: auditory cortex; basolateral amygdala; fear memory; memory consolidation; remote memory; theta activity

\section{Significance Statement}

How and where in the brain do we store the affective/motivational significance of sensory stimuli acquired through life experiences? Scientists have long investigated how "limbic" structures, such as the amygdala, process affective stimuli. Here we show that retrieval of well-established threat memories requires the functional interplay between higher-order components of the auditory cortex and the amygdala via synchrony in the theta range. This functional connectivity is a result of memory consolidation processes and is characterized by a predominant cortical to amygdala direction of information transfer. This connectivity is predictive of the animals' ability to recognize auditory stimuli as aversive. In the absence of this necessary cortical activity, the amygdala is unable to distinguish between frightening and neutral stimuli.

\section{Introduction}

Emotional responses can be elicited by sensory cues that have acquired an affective valence through their association with re- warding or aversive experiences. Memories of emotional experiences are studied using classical Pavlovian conditioning, a procedure in which the subject is exposed to a conditioned stim- 
ulus (CS), such as a tone, in association with an unconditioned stimulus (US), typically a footshock. Following pairing, the CS takes on the affective qualities of the US and it will later, in absence of the US, evoke conditioned emotional responses. Despite a large number of studies, the neural network that stores and retrieves the association between sensory stimuli and the affective/motivational meaning is poorly understood. The amygdala, and particularly its basolateral nuclei (BLA), is necessary for the formation (Miserendino et al., 1990; Wilensky et al., 1999), consolidation (Sacchetti et al., 1999; Schafe and LeDoux, 2000), and long-term storage and retrieval (Gale et al., 2004; Schafe et al., 2005) of fearful memories. On the other hand, recent findings indicated that the neural circuits mediating fearful memories change with time (Sacco and Sacchetti, 2010; Do-Monte et al., 2015). In particular, we found that higher-order sensory cortices, such as the secondary auditory cortex $\mathrm{Te} 2$, are essential during the retrieval of remote $(30 \mathrm{~d})$, but not recent $(24 \mathrm{~h})$ fearful memories (Sacco and Sacchetti, 2010). More recently, it has also been reported that the thalamic pathway to the amygdala is differentially recruited by fear memory retrieval over time (Do-Monte et al., 2015).

Higher-order sensory cortices are reciprocally connected with BLA (McDonald and Jackson, 1987; Kolb and Tees, 1990; Romanski and LeDoux, 1993) and perform high level processing related to complex features of perceived stimuli (Kolb and Tees, 1990), whereas the BLA processes the affective/motivational attributes of emotional experiences (LeDoux, 2000; McGaugh, 2015). Thus, these structures may dynamically interact as a network to permanently store and retrieve fearful memories. Here we addressed this issue by investigating if and how Te 2 and BLA interact in the course of fearful memory retrieval and which functional role can be played by such a connectivity in memory processes.

\section{Materials and Methods}

Subjects. Male Wistar rats (age, 65-80 d; weight, 250-350 g) were used. The animals were housed in plastic cages with food and water available $a d$ libitum, under a $12 \mathrm{~h}$ light/dark cycle (lights on at 7:00 A.M.) at a constant temperature of $22 \pm 1{ }^{\circ} \mathrm{C}$. All experiments were conducted in accordance with the European Communities Council Directive of 24 November 1986 (86/609/EEC) and approved by the Italian Ministry of Health (Authorization 265/2011) and by the Local Bioethical Committee of the University of Turin.

Fear conditioning paradigm: fear memory acquisition. A Skinner box module was used as a conditioning chamber as in previous work (Sacco and Sacchetti, 2010). The floor was made of stainless steel rods $(1 \mathrm{~cm}$ in diameter, spaced $5 \mathrm{~cm}$ apart) connected to a shock delivery apparatus. The apparatus was enclosed within a sound attenuating chamber. Once inside, the animals were left undisturbed for $2 \mathrm{~min}$. After this time, a series of sensory stimuli acting as CSs were administered. The last $1 \mathrm{~s}$ of each CS was paired with a US consisting of a scrambled electric foot shock (intensity, $0.7 \mathrm{~mA}$ ). Rats were left in the chamber for an additional $1 \mathrm{~min}$ and then returned to the home cage. In the fear conditioning to acoustic stimuli, seven pure tones $(8 \mathrm{~s}, 78 \mathrm{~dB}, 3000 \mathrm{~Hz}, 22 \mathrm{~s}$ intertrial interval) were delivered as CSs by a loudspeaker located $20 \mathrm{~cm}$ above the grid floor. In olfactory fear conditioning, seven almond odors (12 s, $48 \mathrm{~s}$ intertrial interval) were presented using a flow-dilution olfactomer. Clean air (1.5 $1 / \mathrm{min}$ ) was directed to a solenoid valve that, when operated, passed the air to a $15 \mathrm{ml}$ bottle containing $10 \mathrm{ml}$ of almond odor. Odorized air was then directed to the conditioning chamber via $1 / 4$ in. Tygon tubing. In the unpaired fear conditioning, seven pure tones $(8 \mathrm{~s}, 78 \mathrm{~dB}, 3000 \mathrm{~Hz}, 22 \mathrm{~s}$ intertrial interval) were delivered as CSs by a loudspeaker located $20 \mathrm{~cm}$ above the floor in a plastic box. Three hours later, animals were put in the conditioning chamber (see above) where 7 shocks ( 1 s, intensity, $0.7 \mathrm{~mA}$ ) were delivered after 2 min every $30 \mathrm{~s}$ (Zhu et al., 2011).
Fear memory retention. The animals were handled for $4 \mathrm{~d}$ ( 5 min per day) before memory retention. Memory was tested in a totally different apparatus located in a separate experimental room to avoid conditioned fear behavior to contextual cues (Sacco and Sacchetti, 2010). The apparatus was a plastic cage with the floor and the sides made of transparent plastic and enclosed within a sound attenuating chamber equipped with an exhaust fan, which eliminated odorized air from the enclosure and provided background noise of $60 \mathrm{~dB}$. Once inside, the subject was left undisturbed for $2 \mathrm{~min}$. After this time, CSs were administered identical to those used during conditioning. The rat behavior was recorded by means of a digital video camera. Freezing was defined as the complete absence of somatic mobility, except for respiratory movements. For each animal, the amount of time (in seconds) spent freezing during the first/last $2 \mathrm{~s}$ of the first CS, the first CS, or all the CSs was measured off-line. Freezing behavior was analyzed by two independent observers who were blind to the animal groups (inter-rater and intra-rater reliabilities $\geq 90 \%$ ). The $120 \mathrm{~s}$ period preceding the first tone was also scored to measure any generalization of fear (pre-CS period). Recent or remote fearful memories were tested $1 \mathrm{~d}$ or 4 weeks after training, respectively.

In vivo local field potential (LFP) recordings and analysis. For recording of extracellular field potentials in freely behaving rats, stainless steel wires were implanted unilaterally (right side). Electrodes were built with five stainless steel wires $(\varnothing 150 \mu \mathrm{m})$ to ensure mechanical stability of the bundle (to obtain straight trajectory in the brain tissue). However, only three of the five wires were connected to a 10-pin connector. Under deep anesthesia, electrodes were stereotaxically implanted in BLA and Te2, according to the following coordinates, in mm: $\mathrm{BLA}, \mathrm{AP}=-2.7, \mathrm{~L}=5.0$, $\mathrm{V}=8.1 ; \mathrm{Te} 2, \mathrm{AP}=-6.6, \mathrm{~L}=6.5$ to $6.7, \mathrm{~V}=6.0$; dorsal hippocampus $\mathrm{AP}=-2.7, \mathrm{~L}=2.0, \mathrm{~V}=3.0$. A silver wire over frontal areas served as reference and ground. All implants were secured using Ketacem cement. After surgery, rats were allowed to recovery for $6-7 \mathrm{~d}$ before testing. All recordings were performed in a customized Faraday chamber. LFPs were recorded and initially digitalized at $1 \mathrm{kHz}$ and stored on a hard drive for offline analysis. The LFPs were very similar across the three channels belonging to the same bundle. For power spectral analysis, we therefore used an average of two channels. For coherence and cross-correlation analysis, we picked one channel randomly. LFP epochs were visually examined, and power spectra of artifact-free segments were computed using fast Fourier transforms by using the commercial software NeuroExplorer (Plexon). Mean power spectra were divided into five frequency bands: $\delta(0.5-3 \mathrm{~Hz})$, low-theta $(3.01-7 \mathrm{~Hz})$, high-theta $(7.01-12 \mathrm{~Hz})$, beta1 $(12.01-20 \mathrm{~Hz})$, and beta2 $(20.01-30 \mathrm{~Hz})$. To focus on the effects of memory recall elicited by the tone in the different areas of interest, an interval of $2 \mathrm{~s}$ at the onset of the first CS was analyzed for each animal. Baseline was evaluated by averaging five $2 \mathrm{~s}$ epochs within the pre-CS period. Relative power was calculated by dividing the absolute amplitude within the aforementioned frequency ranges by the corresponding measures of total amplitude. Spectrograms were calculated using the software NeuroExplorer within the $2-12 \mathrm{~Hz}$ range.

The coherence between LFP channels was measured by magnitude squared coherence (MSC), using the function mscohere in Matlab signal toolbox, which is a coherence estimate of the input signals $x$ and $y$ by using Welch's averaged, modified periodogram method. The MSC estimate is a function of frequency with values between 0 and 1 and indicates how well $x$ corresponds to $y$ at each frequency. Segments of $2 \mathrm{~s}$ duration were split into 3 epochs with 50\% overlap (Lapish et al., 2012). The MSC estimate was calculated over the frequency range of $0.5-30 \mathrm{~Hz}$ for each rat with a frequency resolution of $0.5 \mathrm{~Hz}$. To test whether coherence values were significantly higher than expected by chance, we performed a permutation test in which coherence values were compared before inclusion in additional analyses with a shuffle procedure in which epochs were randomly shifted 5-10 s relative to each other. This process was repeated 1000 times to obtain the distribution of coherence expected by chance. The originals coherence values were considered significant if $>95 \%$ of this randomly generated distribution (Nácher et al., 2013). Baseline was calculated by averaging three $2 \mathrm{~s}$ epochs within the pre-CS period. Differences in coherence were obtained by subtraction of coherence values (CS- pre-CS) and statistics were performed on the average difference in coherence within the frequency bands of interest 
Cross-correlation algorithm was performed using the procedure showed by Adhikari et al. (2010) on instantaneous amplitudes of field potentials, determining the position of the correlation peak as an indicator of information flow between two oscillating signals. The signal was bandpass filtered between 3 and $7 \mathrm{~Hz}$, using the Fieldtrip (Oostenveld et al., 2011) function $f t \_p r e p r o c \_b a n d p a s s f i l t e r$ for zero-phase forward and reverse filter with parameters type='fir', dir='twopass'. The order of the filter $(\mathrm{N})$ was calculated by the function in relation to the length of the trace and the sampling frequency. Analysis were performed on windows of $2 \mathrm{~s}(N=665)$, the instantaneous amplitude of the filtered signals was calculated taking the magnitude of the Hilbert transform of each signal, these amplitudes were cross-correlated and the lag at which the crosscorrelation peak occurs was determined. A positive value of the lag indicates that on average power changes in one region lead power changes in the other, suggesting a predominant directionality in the circuit. The cross-correlation between the instantaneous amplitudes of the LFPs from BLA and Te2 (or hippocampus and Te2) was computed over lags ranging from $-100 \mathrm{~ms}$ to $100 \mathrm{~ms}$. The significance of each crosscorrelation was verified before inclusion in additional analyses using a bootstrap procedure: segments of signals, of the same length as the window to test, were randomly shifted relative to each other 1000 times yielding a distribution of cross-correlation peaks expected by chance. The original cross-correlation was considered significant if its peak value was $>95 \%$ of these randomly generated cross-correlation peaks (Adhikari et al., 2010).

In vivo multiunit activity (MUA) recordings and analysis. MUA in BLA was recorded using six stereotrodes per animal, contained in a 26-gauge stainless steel guide cannula. Stereotrodes were built with tungsten wires ( $\varnothing 12.5 \mu \mathrm{m}$; California Fine Wire) connected to a 16 channels board (EIB-16; NeuraLynx). The remaining two channels were connected to stainless steel wires $(\varnothing 150 \mu \mathrm{m})$ to record LFP activity in Te2. Under deep anesthesia, electrodes were stereotaxically implanted according to the above-cited coordinates. A silver wire over frontal areas served as reference and ground. All implants were dental cemented. For recording, EIB-16 were connected to a headstage (Plexon), connected to a 16channel preamplifier (gain $100 \times$ bandpass filter from $300 \mathrm{~Hz}$ to $9 \mathrm{kHz}$ for MUA, Plexon). Spiking activity and LFP were digitized at $40 \mathrm{kHz}$. Spikes above threshold $(30-40 \mu \mathrm{V})$ and clearly distinguishable from background activity were considered as multiunit. Traces with noise or artifacts were visually detected and excluded.

Data were imported into MATLAB (The MathWorks) for analysis. A combination of custom-written scripts and the Circular Statistics Toolbox (Berens, 2009) were used for the analyses. In detail, the phase of each theta-filtered $(3-7 \mathrm{~Hz})$ sample was extracted from the Hilbert transform, and each spike was assigned the phase of its correspondent field potential sample. Phase-locking was quantified as the circular concentration of the resulting phase distribution, which was defined as the mean resultant length (MRL) of the phase angles. The MRL is the sum of the unit length vectors representing the phases at which each spike occurred, divided by the number of spikes. It therefore takes values between 0 (no phaselocking) and 1 (perfect phase-locking). To analyze the directionality of BLA multiunit phase-locking to Te2 theta, the spike times were lagged relative to the theta filtered signal from -100 to $100 \mathrm{~ms}$, stepping by 20 $\mathrm{ms}$, and the time of the peak MRL value was determined for each multiunit. Multiunits were determined to be significantly phase-locked using a Bonferroni-corrected $p$ value for the Rayleigh $z$ test. The median of the peak MRL times was compared with the null hypothesis of a zero time lag using sign rank and determined to be significant for $p<0.05$. Peristimulus time histograms were generated to $\mathrm{CS}^{+}$sound multiunit activity by analyzing the $z$-score $200 \mathrm{~ms}$ before and $400 \mathrm{~ms}$ after the stimulus onset.

Targeted pharmacological infusion of muscimol into the Te2. For experiments involving muscimol infusion, rats were surgically implanted with bilateral, chronic, intracranial stainless steel guide cannulae (4-mm-long, 26 gauge, Plastic One) aimed $2.1 \mathrm{~mm}$ above the Te2. Cannulae were implanted at the following stereotaxic coordinates: $6.8 \mathrm{~mm}$ posterior to bregma, $\pm 6.5 \mathrm{~mm}$ lateral to midline (Paxinos and Watson, 1986). The cannulae were lowered below the skull surface at an angle of $19^{\circ}$ to the vertical in the coronal plane (medial to lateral). The cannulae were anchored to the skull by two anchor screws and dental cement. Once se-
Table 1. Percentage of freezing to the $\mathrm{CS}^{a}$

\begin{tabular}{lclll}
\hline & CS1 (first 2s) & CS1 (8s) & 7 CSs & CS1 (last 2 s) \\
\hline Naive & $11.9 \pm 4.8$ & $10.4 \pm 4.2$ & $19.6 \pm 2.6$ & $16.1 \pm 6.8$ \\
$24 \mathrm{~h}$ & $52.0 \pm 6.5$ & $57.1 \pm 3.1$ & $68.8 \pm 2.1$ & $70.3 \pm 6.6$ \\
30 d & $45.9 \pm 4.2$ & $46.4 \pm 5.2$ & $61.3 \pm 2.4$ & $71.4 \pm 7.4$ \\
Unpaired & $5.5 \pm 1.8$ & $19.6 \pm 6.3$ & $21.6 \pm 5.5$ & $23.3 \pm 7.7$ \\
Odor & $41.8 \pm 6.6$ & $43.2 \pm 10.3$ & $68.3 \pm 3.2$ & $72.1 \pm 8.6$ \\
Hippo-Te2 & $36.1 \pm 7.4$ & $46.5 \pm 9.8$ & $62.5 \pm 4.7$ & $68.8 \pm 6.9$ \\
\hline
\end{tabular}

${ }^{a}$ Values are mean \pm SEM

cured, cannula dummies (Plastic One) were used to obdurate the guide cannulae. Surgical procedures were similar to those mentioned earlier. After postsurgical recovery ( $8-10 \mathrm{~d})$, injection cannulae (31 gauge) were inserted through the guide cannulae. The injector was connected through polyethylene tubing to a Hamilton syringe (10 $\mu \mathrm{l})$, which was mounted on an infusion pump (Harvard Apparatus). Rats were infused bilaterally with either vehicle $(0.9 \% \mathrm{v} / \mathrm{v} \mathrm{NaCl}, 0.5 \mu \mathrm{l}$ per side $)$ or muscimol $(0.5 \mu \mathrm{l}$ per side, $0.5 \mu \mathrm{g} / \mu \mathrm{l}$ in saline; Tocris Biosciences) at a rate of $0.25 \mu \mathrm{l} / \mathrm{min}$. After waiting for $1 \mathrm{~min}$, the injection cannulae were taken out to allow the drug to diffuse. After the completion of experiments, cannulae placement was confirmed using standard histological methods. The spread of muscimol action within the Te2 was also estimated qualitatively using fluorescently labeled muscimol $(0.5 \mu \mathrm{g} / \mu \mathrm{l}$ in saline, $0.5 \mu \mathrm{l}$ per side, Invitrogen).

Startle analysis. The acoustic startle response was measured as an input-output function (Valsamis and Schmid, 2011) into a startle chamber (SPSG). After an acclimation period of $5 \mathrm{~min}$ with a constant background white noise of $50 \mathrm{~dB}$, startle stimuli (1 s white noise) was displayed every $20 \mathrm{~s}$, starting at $57 \mathrm{~dB}$. Startle stimulus intensity increased between each stimulus until reaching $88 \mathrm{~dB}$, resulting in 10-30 trials with startle stimuli (Sacco and Sacchetti, 2010).

Histology. The needle track in the case of muscimol injections and electrode placements lesions was histologically verified at the end of the experiments with Nissl staining, using the conventional procedure; the spread of fluorescent muscimol was determined by observing mounted slides in a stereo-microscope (Leica, MZ16FA) equipped with a fluorescent lamp (Hg, $100 \mathrm{~W}$ ) and a digital camera (Leica, DFC360FX).

Statistical analyses. Student's $t$ test, one-way ANOVA, and NewmanKeuls multiple-comparisons test were used for comparing freezing responses in the different behavioral groups. To assess electrophysiology data, we used the nonparametric Kruskal-Wallis test followed by the unpaired Mann-Whitney or paired Wilcoxon signed-rank test, depending on the analysis. Three-way ANOVA for repeated measures was used for input-output auditory curves. Spearman correlation was used for electrophysiological and behavioral correlations.

\section{Results}

\section{Te2 and BLA interplay during recent and remote fearful memory retrieval}

As a first step, we investigated if and how the neural activity in the BLA and Te 2 changed during the retrieval of recent and remote auditory threat memories. Memory retention was tested $24 \mathrm{~h}$ $(n=14)$ or $30 \mathrm{~d}(n=24)$ after training by measuring freezing behavior before and during the presentation of CSs previously paired with US (Sacco and Sacchetti, 2010). At both time intervals, conditioned rats showed significant freezing responses compared with naive animals $(n=18)$, which had never received the tone previously, and with unpaired animals $(n=18)$ that were exposed to explicitly unpaired presentations of the CS and US (Table 1). One-way ANOVA showed differences among groups in the freezing response during the first $2 \mathrm{~s}$ of the first CS $\left(F_{(3,70)}\right.$ $=26.23 ; p<0.001)$. Student-Newman-Keuls revealed differences between conditioned $30 \mathrm{~d}$ and conditioned $24 \mathrm{~h}$ groups with respect to naive and unpaired rats $(p<0.05)$. Similar results were obtained by analyzing freezing responses during the entire period of the first CS $\left(8 s ; F_{(3,70)}=18.59 ; p<0.001\right)$ and during 


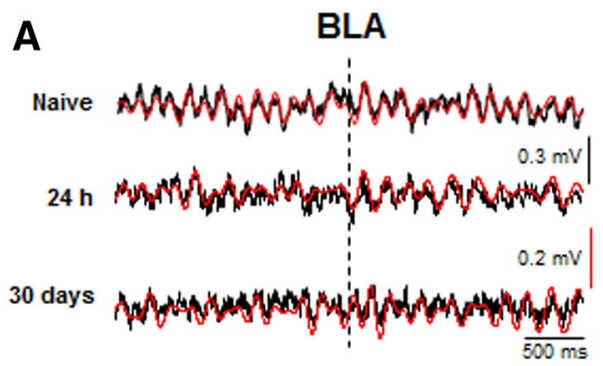

B Te2

C

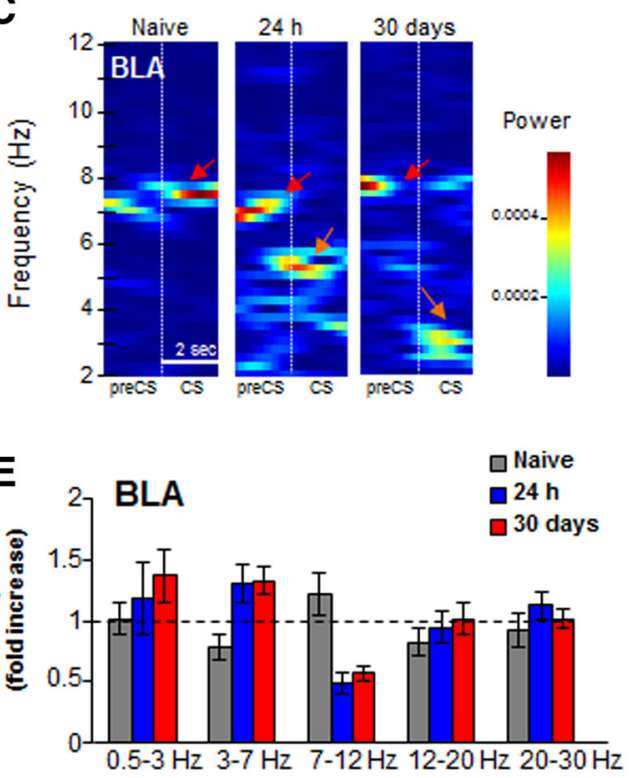

D

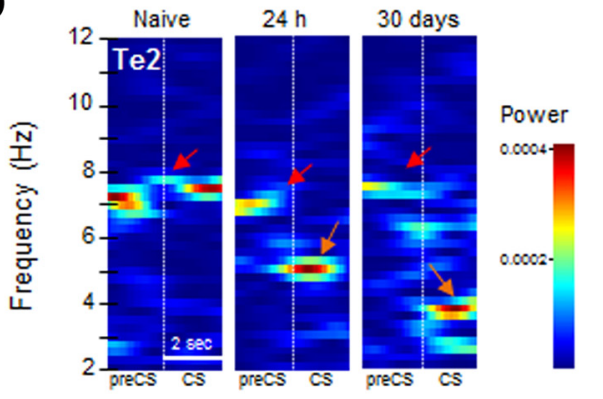

$\mathbf{F}$
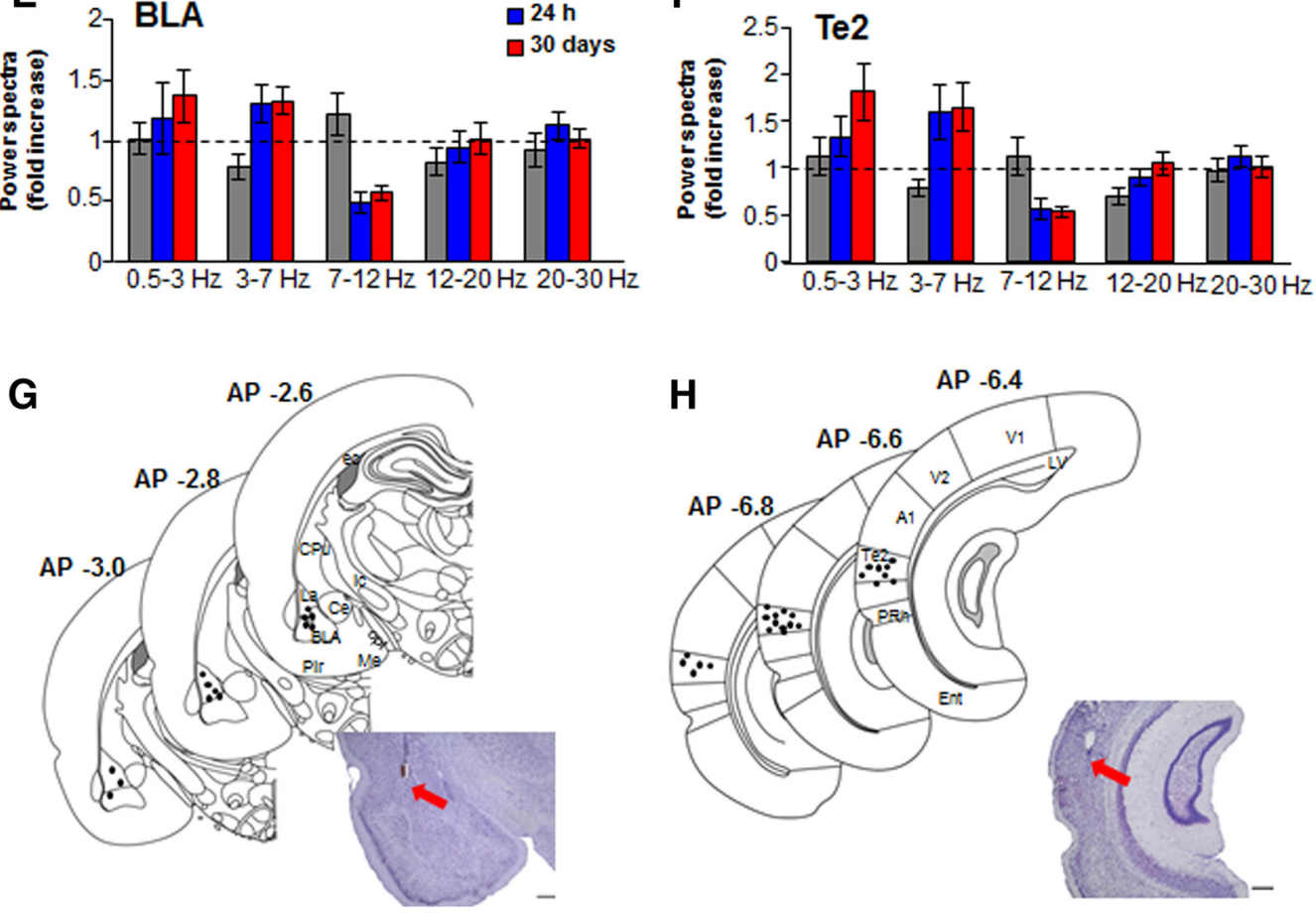

Figure 1. Neural activity in BLA and Te2 during recent and remote fearful memory recall. Example of LFP traces recorded in BLA ( $\boldsymbol{A})$ and in Te2 (B) in a naive (top), $24 \mathrm{~h}$ (middle), and $30 \mathrm{~d}$ rat (bottom) with their low theta (3-7 Hz) filtered signal superimposed (in red) around the first CS (vertical dotted line). $\boldsymbol{C}, \boldsymbol{D}$, The respective spectrograms around the onset ( $2 \mathrm{~s}$ before, pre-CS, and during, $(S)$ of the first $C S$ (white dotted line). Red and orange arrows point to high- and low-theta activity, respectively. $\boldsymbol{E}, \boldsymbol{F}$, Theta activity changes are statistically different in both BLA (E) and Te2 $(\boldsymbol{F})$, when comparing LFPs of the $\mathrm{CS}$ with pre-CS activity in naive rats $(n=18)$ and in those retrieving recent $(n=14)$ versus remote $(n=24)$ memories at both low-theta $(3-7 \mathrm{~Hz})$ and high-theta $(7-12 \mathrm{~Hz})$. No differences were found between naive and conditioned rats in the $\delta$, beta1, and beta2 bands in all instances. All data are mean \pm SEM. $G, \boldsymbol{H}$, Location of electrode tips for LFPs recordings in BLA (G) and in Te2 $(\boldsymbol{H})$, in the $30 \mathrm{~d}$ group. Both have on the right a representative histology of electrode tracks. Scale bars, $450 \mu \mathrm{m}$. A1, Primary auditory cortex; (e, central amygdala; CPU, caudate-putamen (striatum); ec, external capsule; Ent, entorhinal cortex; ic, internal capsule; La, lateral amygdala; LV, lateral ventricle; Me, medial amygdala; opt, optic tract; Pir, piriform cortex; PRh, perirhinal cortex; Te2, secondary auditory cortex; V1 and V2, primary and secondary visual cortices. Plates are adapted from the atlas of Paxinos and Watson (1986). Te2 was defined according to the atlas of Zilles (1985).

the total 7CSs $\left(F_{(3,70)}=58.03 ;<0.001\right)$. In these animals, LFPs were recorded in Te2 and BLA (Fig. $1 A, B$ ). To minimize the effects of several confounding factors that may occur during the overall CS administration, such as second-order conditioning due to the fear state in a new environment (Gewirtz and Davis, 2000) or even extinction mechanisms elicited by continued CS presentation in the absence of the US, we circumscribed our analysis to the initial period of the first CS. An interval of $2 s$ at the onset of the first CS was then analyzed for each animal. Relative power was calculated by dividing the absolute amplitude within the frequency bands $\delta(0.5-3 \mathrm{~Hz})$, low-theta $(3.01-7$ $\mathrm{Hz})$, high-theta $(7.01-12 \mathrm{~Hz})$, beta1 $(12.01-20 \mathrm{~Hz})$, and beta2 
A
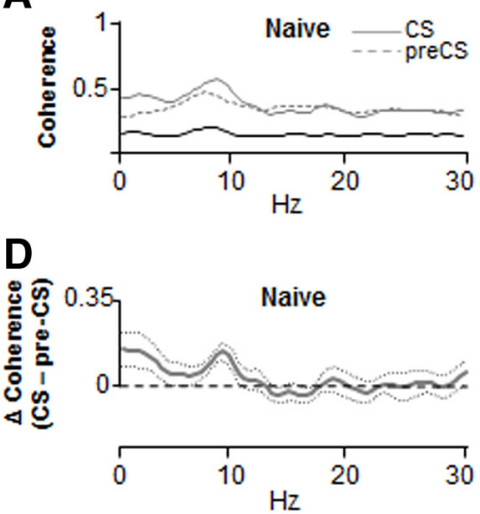

G

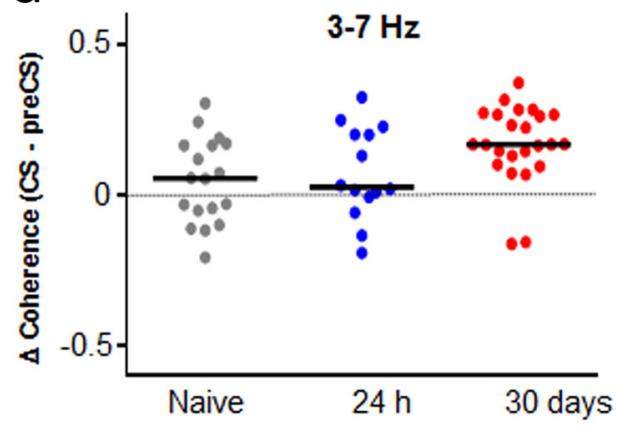

B



E

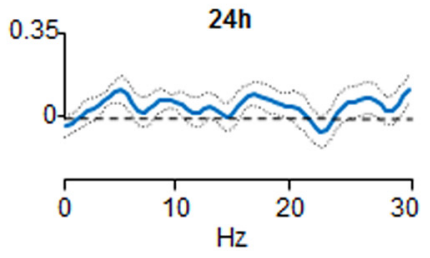

C

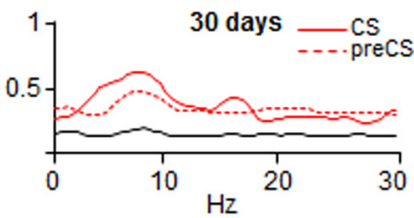

$\mathbf{F}$

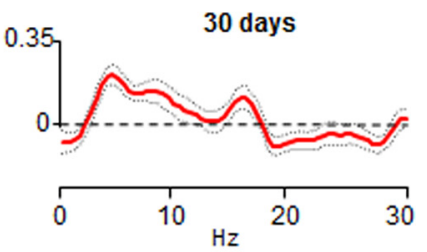

$\mathrm{H}$

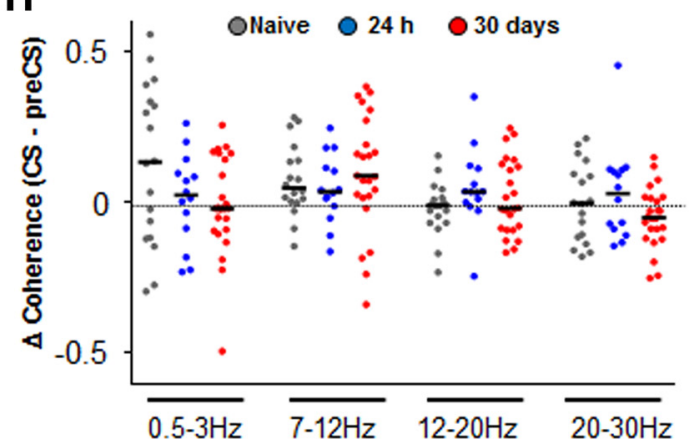

Figure 2. Te2-BLA increased synchrony at remote threat-memory retrieval. Coherence between the BLA and the Te2 during the $C S$ onset (filled line) with respect to baseline (pre-CS, dotted line) in naive rats $(\boldsymbol{A}, n=18)$, in animals retrieving fearful memories $24 \mathrm{~h}(\boldsymbol{B}, n=14)$ or $30 \mathrm{~d}(\boldsymbol{C}, n=24)$ after training. Black line indicates the coherence expected by chance. $\boldsymbol{D}-\boldsymbol{F}$, The coherence difference between the $C S$ and the pre-CS period ( $\Delta$ Coherence) increases only in the $30 \mathrm{~d}$ group, with a peak at $4.5 \mathrm{~Hz}(\boldsymbol{F})$, if compared with naive $(\boldsymbol{B})$ or $24 \mathrm{~h}$ recall animals $(\boldsymbol{D})$. Theta coherence between Te2 and BLA is significantly higher during remote memory recall in low-theta range with respect to the naive and the $24 \mathrm{~h}$ groups $(\boldsymbol{G})$, but not in the other frequency ranges $(\boldsymbol{H})$. Each dot is a single animal. Black line indicates the median value.

(20.01-30 Hz) by the corresponding measures of total amplitude during the pre-CS period. Animals retrieving recent or remote memories showed significantly different CS-evoked BLA and Te2 LFP power within both low- and high-theta frequency bands (Kruskal-Wallis, $p<0.05$ ) but not in the $\delta$, beta 1 , or $\beta 2$ bands (Kruskal-Wallis, $p>0.05$, not significant) compared with naive rats (Fig. $1 C-F$ ). In the theta range, we found an increase in CS-evoked low-theta and a decrease in high-theta power in both BLA (Fig. $1 A, C, E, G$ ) and Te2 (Fig. $1 B, D, E, H$ ) at recent and remote memory recall (sign rank, $p<0.05)$. Our data are in line with previous studies showing that low-theta activity is elicited in BLA and hippocampus when animals are freezing during recall of a recent fear memory (Seidenbecher et al., 2003; Narayanan et al., 2007; Popa et al., 2010), whereas high-theta activity is supposed to be a prominent feature of the hippocampal LFP during exploration (Buzsáki, 2002, 2006).

The BLA and $\mathrm{Te} 2$ are reciprocally anatomically connected (McDonald and Jackson, 1987; Romanski and LeDoux, 1993), and the similarity between theta changes in the BLA and Te2 suggests that LFPs from these areas may be highly synchronized. Therefore, we examined whether changes in CS-evoked theta activity were accompanied by an increase in coherence between BLA and Te2 and whether such synchrony was recruited differentially at various times after learning. In naive rats and in animals retrieving recent $(24 \mathrm{~h})$ and remote $(30 \mathrm{~d})$ memories, the coherence between BLA and Te2 before and during the CS onset was significantly higher than expected by chance (permutation tests, $p<0.05$ in all instances; Fig. $2 A-C$ ). When comparing the coherence during the CS onset with respect to the pre-CS, we found higher levels of coherence in the remote fear memory recall group (Fig. $2 F$ ), whereas recent recall resulted in coherence levels that were similar to the naive group (Fig. $2 D, E$ ). Indeed, a significant difference among groups was observed in the 3-7 Hz range (Kruskal-Wallis test, $p<0.05$; Fig. $2 G$ ) but not in the other frequency ranges (Kruskal-Wallis test, $p>0.05$; Fig. $2 H$ ). Within the low theta range, despite increased activity in both BLA and Te2 detected $24 \mathrm{~h}$ after training, the coherence in this group (median, 0.055) was not different with respect to naive rats (median, 0.026, Mann-Whitney test, $p>0.05$; Fig. 2G). Conversely, in animals retrieving remote memories, the coherence between Te2 and BLA in the low-theta range was significantly enhanced (median, 0.168) with respect to both naive (Mann-Whitney test, $p<0.05$ ) and 24 h groups (Mann-Whitney test, $p<0.05$ ), with a maximal peak around the $4.5 \mathrm{~Hz}$ frequency (Fig. $2 F$ ).

These findings revealed that, $30 \mathrm{~d}$ after training, Te 2 and BLA activity is more synchronized at lower theta frequencies than it is during the $24 \mathrm{~h}$ recall of recently formed memories. Given that conditioned freezing was similar in animals tested at recent and remote time points (Table 1), the change in coherence detected only at the remote time point is not due to a difference in behavioral state or sensitivity to the auditory CSs. To better define whether such a Te2-BLA synchrony was mainly related to associative mnemonic processes, we repeated our experiments in rats that were exposed to explicitly unpaired presentations of the CS and US. At the same $30 \mathrm{~d}$ recall time point, these animals did not show CS-elicited freezing (Table 1) and theta synchrony in the low theta range (me- 
dian, -0.044) did not differ from that of naive rats (Mann-Whitney test, $p>$ 0.05; Fig. $3 A, B, G)$. In addition, we performed a similar analysis in animals conditioned to odor CSs $(n=11)$, a process in which the Te2 is not involved (Sacco and Sacchetti, 2010). This group displayed conditioned freezing to the odor CSs (Table 1) but no evidence of increased low theta coherence in the Te2-BLA circuit (median, 0.093) compared with naive rats (Mann-Whitney test, $p>0.05$; Fig. $3 C, D, G)$. To investigate whether the increased functional connectivity was circumscribed to the neural network specifically engaged by cued memory processes, we measured the coherence between Te2 and the dorsal hippocampus, a region necessary for contextual, but not auditory, fear memory (Kim and Fanselow, 1992; Sacchetti et al., 1999; LeDoux, 2000). Despite the high level of conditioned freezing to the CSs in conditioned rats (Table 1), the $\mathrm{Te} 2$ and hippocampus did not show any increase in CS-evoked coherence during remote auditory memory recall ( $n=9$; median, 0.055; Mann-Whitney test, $p>0.05$; Fig. $3 E-G$ ).

Collectively, these findings indicate that during the retrieval of remote, but not recent auditory fear memories, the $\mathrm{Te} 2$ and BLA become highly synchronized in the low-theta $(3-7 \mathrm{~Hz})$ frequency range and that this Te2-BLA increase in synchrony is cue and area specific. Critically, because these two areas were not synchronized shortly after training, theta synchrony at the remote time point suggests functional connectivity stemming from memory consolidation.

Te2-BLA directionality during remote fear memory retrieval We next addressed the crucial question of the direction, if any, of information transfer between the BLA and Te2 during memory retrieval. Are emotional memories stored both at the level of cortex and the BLA, and do these structures communicate reciprocally during remote memory recall? Or, alternatively, is one of these sites conveying signals to the other structure? To address this issue, we recorded Te2 and BLA LFP oscillations for a crosscorrelation of power analysis (Adhikari et al., 2010, 2011; Likhtik at al., 2014). We analyzed the position (or "lag") of the power correlation peak; a positive value of the lag indicates that on average power changes in one region lead power changes in the other, suggesting a predominant directionality in the circuit (Adhikari et al., 2010, 2011; Likhtik at al., 2014). Notably, variability in power does not affect the directionality estimate, and the crosscorrelation lag has been shown to be robust to different levels of the signal-to-noise ratio between signals (Adhikari et al., 2010). Given that oscillations in the low-theta range showed the most prominent stimulus-processing related power and coherence changes, LFPs measured during the initial remote memory recall were bandpass filtered for low-theta (see Materials and Meth-
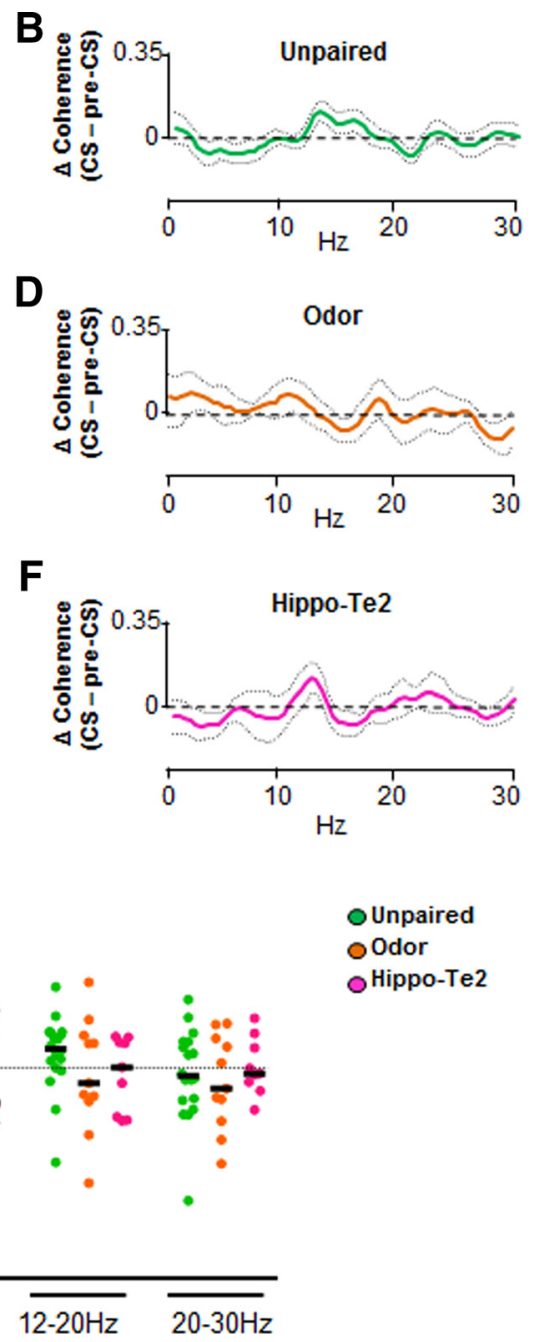

Figure 3. Coherence is specific for remote $C S$ memory recall between Te2 and BLA. Coherence values are similar during the CS and after tone conditioning $(\boldsymbol{C}, n=9)$. Black line indicates the coherence expected by chance. The coherence difference between the CS and the pre-CS period ( $\Delta$ Coherence) does not differ in all the observed groups $(\boldsymbol{D}-\boldsymbol{F})$ for all the frequency ranges $(\boldsymbol{G})$. Each dot is a single animal. Black line indicates the median value.

ods). From a total of 24 rats, a time-lag analysis of peak crosscorrelation activity revealed that $62.5 \%$ of the animals ( $n=15$ of 24) showed a predominant Te2-to-BLA lead in activity during CS retrieval (Fig. $4 A-E$ ), whereas $8.3 \%$ (2 of 24) showed a BLA-toTe2 lead in activity and $29.2 \%$ ( 7 of 24$)$ did not have a predominant directionality of information flow (Fig. $4 E$ ). Overall, from the 17 of 24 animals that showed a significant lead in any direction (15 Te2-to-BLA and 2 BLA-to-Te2), initial recall of remote memories was dominated by a Te2-to-BLA directionality of information transfer, with a significant median time lag of $10.66 \mathrm{~ms}$ (sign-rank, $p<0.01$; Fig. $4 C$ ). Collectively, these data suggest that the recall of well-stored fearful memories first recruits the sensory cortex, which subsequently conveys the signal to the BLA.

Next, we were interested in the behavioral significance of increased Te2-to-BLA communication during CS retrieval. To this end, we plotted the latency to display conditioned freezing as a function of the percentage of time the Te2 led the BLA during the onset of the first CS (first $2 \mathrm{~s}$ of CS). Intriguingly, we found that increased Te2-to-BLA directionality during CS recall significantly correlated with a faster latency to freeze to the CS (Spearman correlation; $p<0.001$ ) (Fig. $4 F$ ). Notably, this correlation 

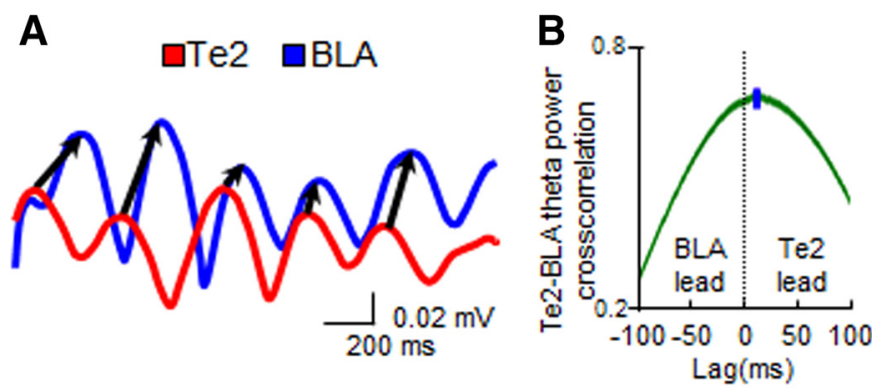

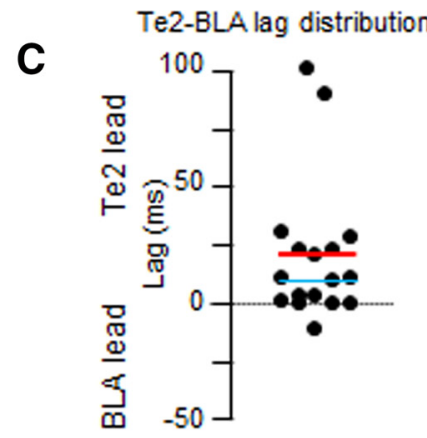

E

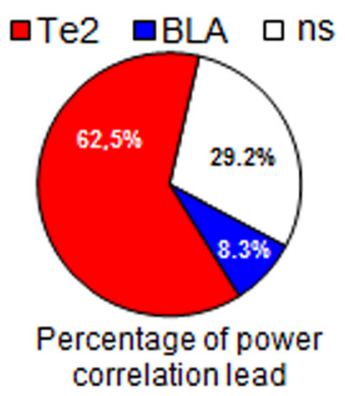



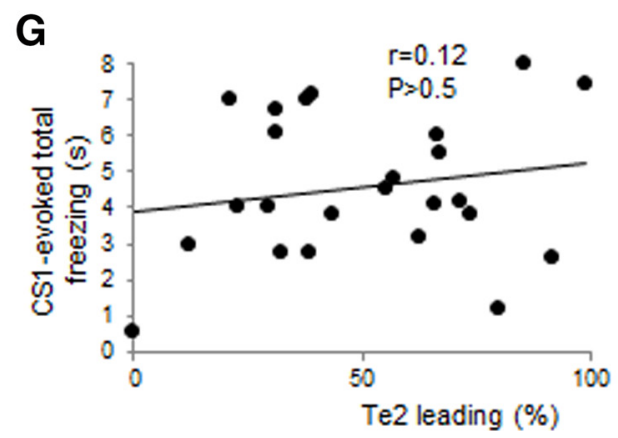

Figure 4. Te2-to-BLA information flow characterizes remote threat memory retrieval. Power cross-correlation analysis was performed within the 3-7 Hz range. $\boldsymbol{A}$, Example of filtered LFPs illustrating the power cross-correlation lag analysis during the first $2 \mathrm{~s}$ of the first CS. Arrows go from the leading (red) to the lagging (blue) area. B, Example of BLA-Te2 low-theta power cross-correlation during remote memory recall. The cross-correlation peaks at a positive lag, indicating that changes in low-theta power occur first in Te2 and then in BLA. C, Scatter plot showing the distribution of lags at the maximal cross-correlation of LFP power during remote memory retrieval ( $n=17: 15$ with Te2 leading and 2 with BLA leading activity). Red and blue lines indicate mean and median, respectively. $\boldsymbol{D}$, Fine-scale switches in power cross-correlation lags; example showing that the $C S$ onset is associated with an increased percentage of Te2 leading activity. $\boldsymbol{E}$, Percentage of animals where the Te2 leads the BLA ( $n=15$ of 24), compared with BLA leading the Te2 $(n=2)$, or animals with no significant lead $(n=7)$. $\boldsymbol{F}, \boldsymbol{G}$, The percentage of time Te2 leads BLA within first CS onset correlates with the latency to display freezing behavior during the first CS presentation $(\boldsymbol{F})$, but not with the overall amount of freezing during the first $(S(G)$. Each black dot represents a single animal $(n=24)$.

was still significant if the longest latency $(7.9 \mathrm{~ms})$ data point was removed $(N=23, r=0.59, p=0.0028$, data not shown). In contrast, the percentage of time the Te 2 led the BLA did not significantly correlate with the percentage freezing elicited by the first CS (Spearman correlation, $p>0.05$; Fig. $4 G$ ). The data suggest that $\mathrm{Te} 2$ conveys signals to the BLA, which determine animals' capacity to recognize aversive CSs and therefore to respond rapidly with defensive behaviors. Conversely, Te2-to-BLA information transfer does not determine the overall strength of the expressed fear behavior, a process that may rely on other cortical and thalamic inputs to the amygdala network (Courtin et al., 2014; Herry and Johansen, 2014; Likhtik at al., 2014; Likhtik and Paz, 2015).

To further probe the role of Te2-BLA interactions in memory recall, we analyzed Te2-BLA activity once the memory had been already retrieved (i.e., during the last $2 \mathrm{~s}$ of the first CS presentation). Compared with naive and unpaired animals, conditioned rats still evidenced a high level of freezing response during this later period $\left(F_{(2,57)}=21.90 ; p<0.001\right)$ (Table 1$)$. Moreover, in the $30 \mathrm{~d}$ group, LFP CS-evoked theta power was similar to that recorded during the first $2 \mathrm{~s}$ for both BLA $(1.29 \pm 0.11 \mathrm{vs} 1.36 \pm$ 0.24 Wilcoxon matched-pairs signed rank test; $p>0.05)$ and Te2 $(1.46 \pm 0.18$ vs $1.33 \pm 0.17$ Wilcoxon matched-pairs signed rank test; $p>0.05)$. However, theta coherence during the last $2 \mathrm{~s}$ of the first CS was similar among naive (Fig. $5 A, B$ ), unpaired (Fig. $5 C, D$ ), and conditioned (Fig. $5 E, F$ ) rats (Kruskal-Wallis, $p>$ 0.05 ; Fig. $5 G$ ). Thus, in the same animals ( $30 \mathrm{~d}$ retrieval group), Te2-BLA theta coherence increased during the initial process of remote memory retrieval (i.e., during the first $2 \mathrm{~s}$ of the first CS) but not at the end of the same CS (sign-rank, $p<0.05$; Fig. $5 H$ ). Further supporting the specific involvement of $\mathrm{Te} 2$ in the initial stages of remote memory recall, power cross-correlation analyses of low theta power changes between the two areas showed that Te2 leads the BLA three times more in the first $2 \mathrm{~s}$ of the CS 
compared with the last $2 \mathrm{~s}$ of the CS (62.5\% vs $20.8 \%$ of the time, Fig. $4 E$ compared with Fig. 5I). Notably, the percentage of time the amygdala led the Te 2 did not change between the first and last $2 \mathrm{~s}$ of the CS $(8.3 \%$ and $8.4 \%$ of the time, respectively; Figs. 4E, 5I, blue).

\section{Te2-BLA synchrony reflects local activity in $\mathrm{Te} 2$ and $\mathrm{BLA}$ regions}

LFP represents a suitable method to get important insights into memory processes that likely result from integrative population activity (Buzsáki et al., 2012; Barbieri et al., 2014). However, LFP recordings are susceptible to volume conduction, raising questions as to the origin of theta frequency oscillations detected during recall. The lack of hippocampalTe2 synchrony during recall suggests that Te2-BLA theta synchronization, when present, is not due to contamination by volume-conducted signals from distant sites or signals in the reference wire. However, volume conduction could still be an issue for BLA recordings, particularly because it is adjacent to the perirhinal cortex, which is part of the auditory processing stream (Romanski and LeDoux, 1993; Sacchetti et al., 1999; LeDoux, 2000). We therefore recorded MUA in the BLA in a subset of conditioned $(n=11)$ and unpaired $(n=7)$ animals to eliminate volume conduction as a potential confound. In comparison with rats that heard unpaired stimuli, BLA spikes in conditioned animals were better phase-locked to the ongoing Te2 theta signal, and tended to occur more frequently near the trough of the Te2 theta oscillation (Fig. $6 A, B)$, as assessed by the MRL statistic (Fig. 6C), a measure of circular concentration (Likhtik at al., 2014). When considering all the analyzed animals regardless of whether their BLA firing was significantly phase-locked to the $\mathrm{Te} 2$, the fold change in the MRL of MUA phase-locking in conditioned rats at the remote time point was statistically different from $1(2.01 \pm 0.33$, sign-rank, $p<0.05)$ and from the unpaired rats $(1.13 \pm 0.3$, sign-rank, $p<0.05)$ (Fig. $6 C$ ). Similar results were obtained when considering only the electrodes where MUA was significantly phase-locked to the $\mathrm{Te} 2(n=9$ and $n=3$ in the $30 \mathrm{~d}$ and unpaired groups, respectively; Fig. $6 C$, inset). Collectively, these findings support the view that enhanced synchronization of the Te2-BLA circuit is due to a Te2-BLA interaction and not to inputs from other regions. Moreover, they are consistent with the coherence data, reinforcing the notion that the BLA and Te2 work together to dynamically retrieve learned threat signals.

We then inferred the temporal relationship of Te2-BLA connectivity during CS presentations by determining the lag at which phase-locking of BLA multiunits to Te2 low-theta tends to be maximal (Likhtik at al., 2014). In conditioned rats, we found that BLA MUA showed a statistically significant Te2 lead in activity (sign rank, $p<0.05$ ), suggesting a predominant Te2-to-BLA compare with Fig. 4E).
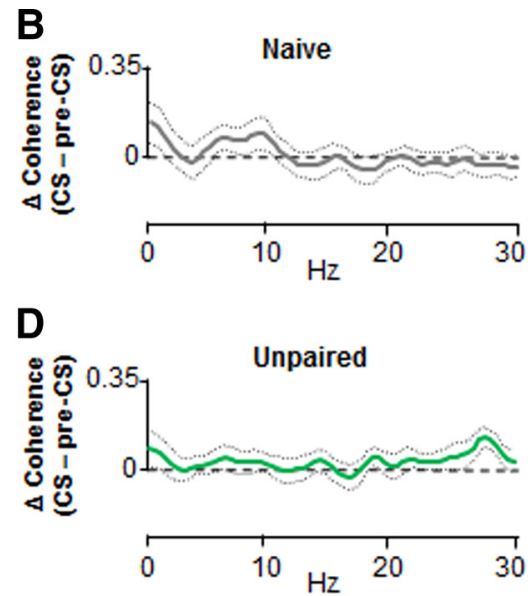

$\mathbf{F}$


Figure 5. Te2 and BLA coherence is specific to the tone onset. $\boldsymbol{A}-\boldsymbol{F}$, Naive $(n=18)$, unpaired ( $n=18)$, and $30 \mathrm{~d}(n=24)$ animals do not show an increased coherence during the last $2 \mathrm{~s}$ of the first $\mathrm{CS}$ with respect to baseline. Black line indicates the ue. $\boldsymbol{H}$, In the $30 \mathrm{~d}$ group, low theta range coherence shows a marked reduction during the first and last $2 \mathrm{~s}$ of the first $\mathrm{CS}$ (red represents average values) and the vast majority of animals exhibited no significant leading activity between Te2 and BLA ( $\boldsymbol{I}$

directionality, again consistent with the LFP findings (Fig. $6 D-F)$.

\section{Te2 local activity is required for BLA CS-evoked activity and for remote fear memory retrieval}

So far, our evidence has mainly been correlative. It remains unknown whether Te2 plays a causal role in leading BLA activity during emotional memory retrieval. To address this issue, we tested whether the inactivation of Te2 during the recall of remote fearful memories affects BLA activity. Te2 was inactivated through the local injection of the $\mathrm{GABA}_{\mathrm{A}}$ (GABA)-receptor agonist muscimol $(0.5 \mu \mathrm{g} / \mu \mathrm{l}, 0.5 \mu \mathrm{l}$ bilaterally) (Martin and Ghez, 1999; Letzkus et al., 2011) 1 h before remote memory recall. The spread of muscimol within the Te2 was estimated qualitatively using fluorescently labeled muscimol (Letzkus et al., 2011) (Fig. $7 A$ ), although the fluorescent molecule is larger than the molecule of muscimol and therefore the extent of the effective spread may be underestimated. When compared with conditioned saline-injected and unpaired animals, conditioned muscimolinjected rats showed strongly reduced fear levels (Fig. $7 B-D$ ). 
A

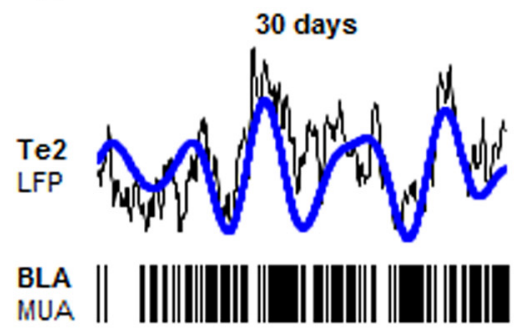

100 ms
B
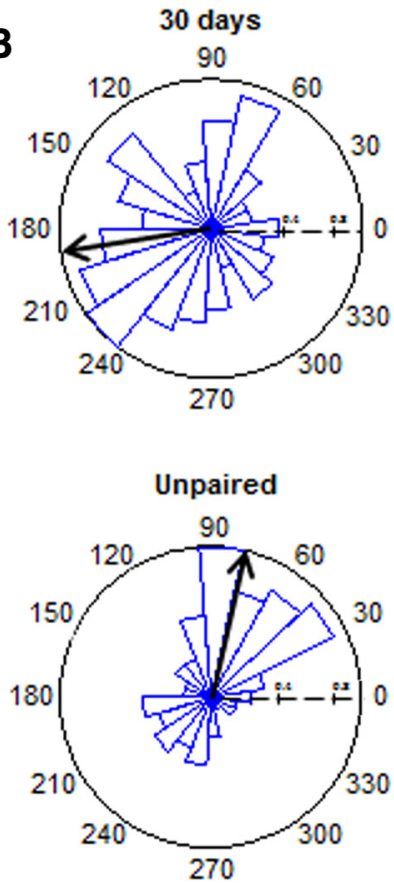

C
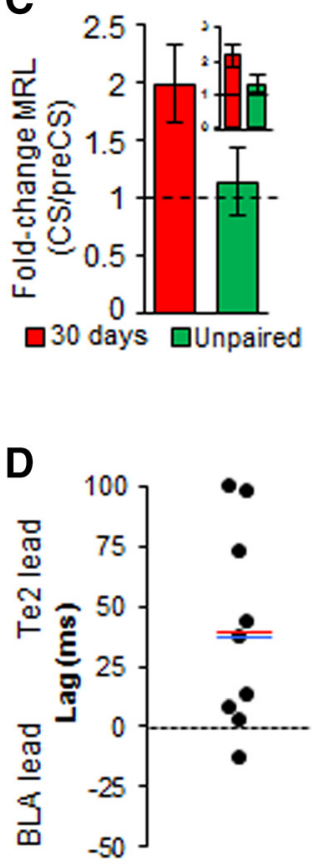

$E$

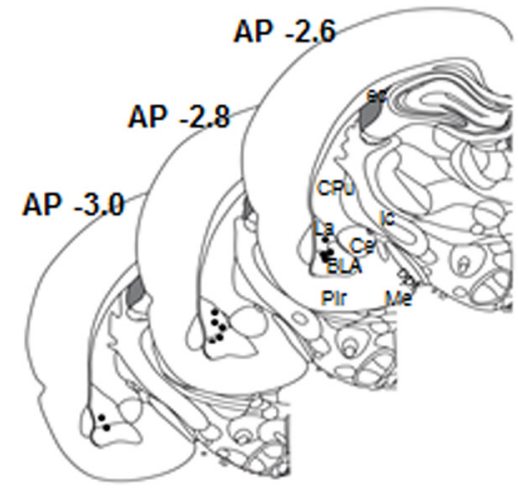

$\mathbf{F}$

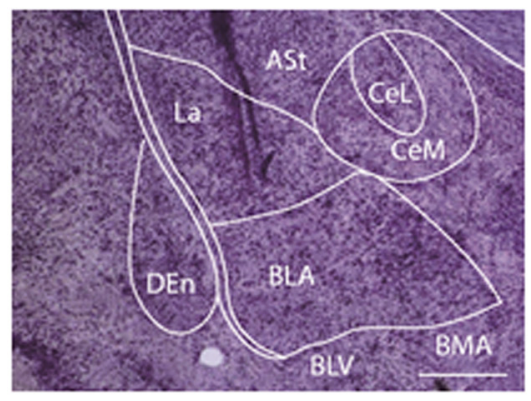

Figure 6. BLA multiunits are phase-locked to Te2 LFP during fearful memory recall. A, Example of a raw (black) and theta-filtered (blue) Te2 LFP trace with recorded MUA in BLA for $30 \mathrm{~d}$ group (top, $n=11$ ) and unpaired group (bottom, $n=7$ ). B, Distribution and mean (black arrow) of theta phases for the same recordings. C, Fold change in the strength of MUA phase-locking in $30 \mathrm{~d}$ ( $n=$ 11 ) and unpaired $(n=7)$. Inset, Fold change with significant units only ( $n=9$ and $n=3$, respectively). D, Distributions of lags at which peak phase-locking occurred, for significant units only $(n=9)$. Red and blue dashes indicate mean and median, respectively. $\boldsymbol{E}$, Location of electrode tips for MUA recordings in BLA $(n=11)$. $\boldsymbol{F}$, Representative histology of electrode tracks. Scale bar, $400 \mu \mathrm{m}$.

During the onset of the first CS, one-way ANOVA revealed significant differences in freezing among groups $\left(F_{(2,26)}=27.51\right.$, $p<0.0001)$. The Newman-Keuls post-test indicated differences between conditioned freezing in saline-injected animals $(n=11)$ and the other groups $(p<0.001)$, but not between conditioned freezing in muscimol-injected $(n=11)$ rats and in the unpaired group $(n=7)(p>0.05)$ (Fig. $7 B)$. Similar results were detected in the percentage of freezing expressed during the entire $8 \mathrm{~s}$ of the first CS $\left(F_{(2,26)}=26.65, p<0.0001\right.$; Fig. $\left.7 C\right)$ and when considering all of the $7 \mathrm{CSs}\left(F_{(2,26)}=30.33, p<0.0001\right.$; Fig. $\left.7 D\right)$. These data suggest that the $\mathrm{Te} 2$ stores memory information that is crucial for remote retrieval. Another alternative is that Te2 inactivation could produce impaired sensory perception, thereby adversely impacting the transmission of auditory information to the BLA. To investigate this possibility, we analyzed the auditory input-output curve by obtaining startle responses as a function of auditory stimulus intensity (dB) (Valsamis and Schmid, 2011). Three-way ANOVA revealed no differences among groups $\left(F_{(2,19)}=\right.$
$0.47 ; p>0.05)$ before and after injection $\left(F_{(2,16)}=0.09 ; p>0.05\right)$ (Fig. $7 E$ ). The acoustic stimuli used in the startle paradigm differed from those presented in the fear conditioning experiments (a white noise vs a pure tone). Therefore, we verified the impact of $\mathrm{Te} 2$ inactivation on remote fear memories produced by the association of white noise CSs with footshock (US). Again, muscimol-injected rats showed amnesia, as shown by the low percentage of freezing response during the first CS $(8 \mathrm{~s} ; t$ test, $p<0.05)$ (Fig. $7 F$ ) and during the total CSs ( $t$ test, $p<0.01$ ) (Fig. $7 G$ ).

We then analyzed BLA activity in the muscimol-injected rats as well as in conditioned saline-injected animals and in the unpaired group. Peristimulus time histogram of the BLA MUA showed that only fear conditioned rats had a CS-driven increase in BLA firing rates ( $\operatorname{sign}$ rank, $p<0.01$ ), whereas the muscimolinjected animals and the unpaired rats did not differ from each other (sign rank, $p>0.05$ ) (Fig. $7 H, I$ ). Collectively, these data indicate that $\mathrm{Te} 2$ blockade impairs remote memory retrieval and prevents any recall-evoked activity in BLA. Indeed, in this condi- 
A

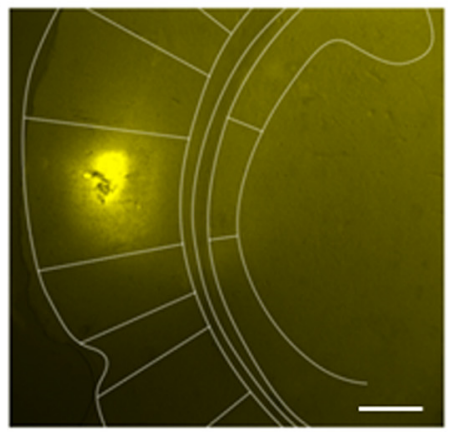

E

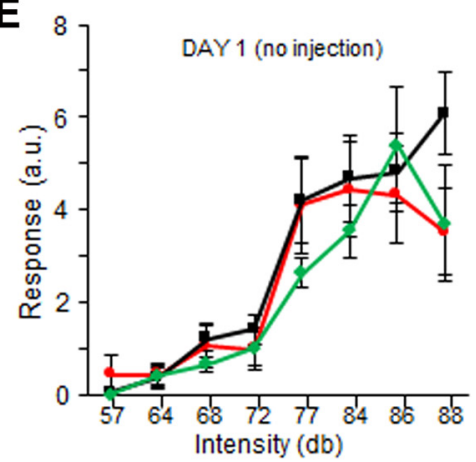

B
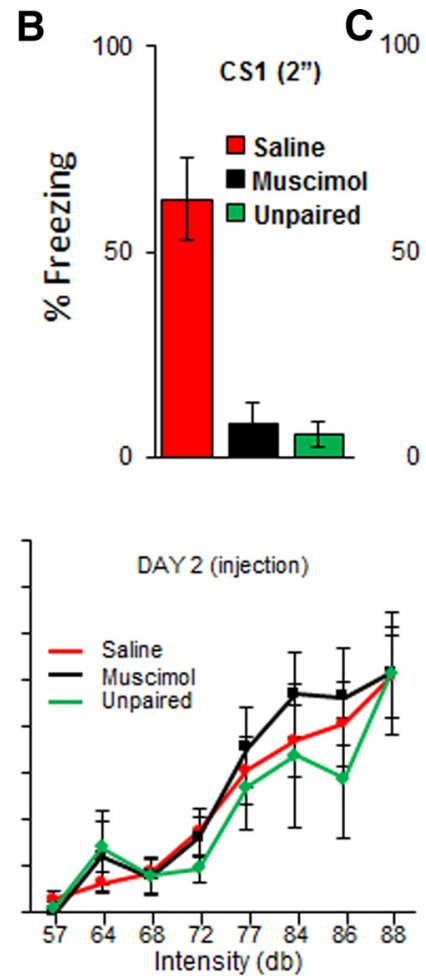

$\mathbf{C}_{100}$

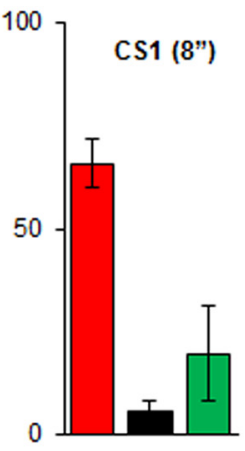

$\mathbf{D}_{100}$

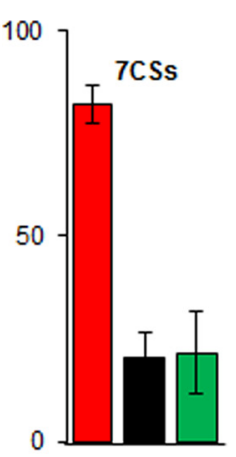

F



H

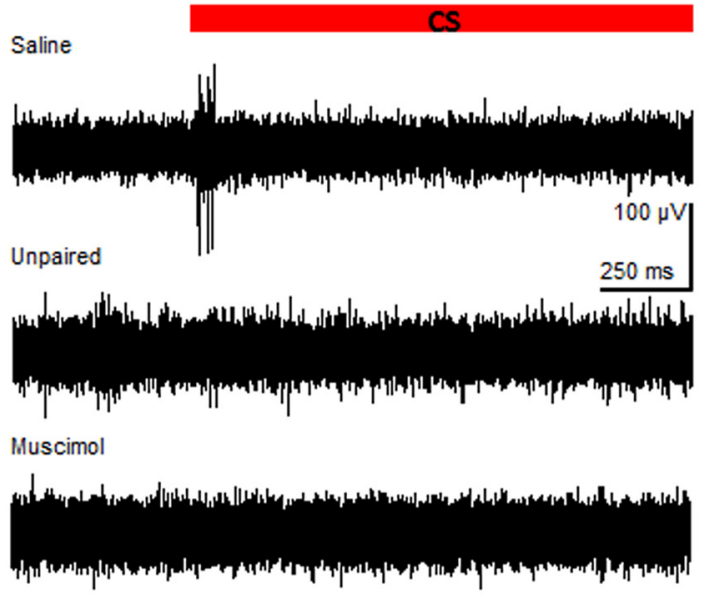

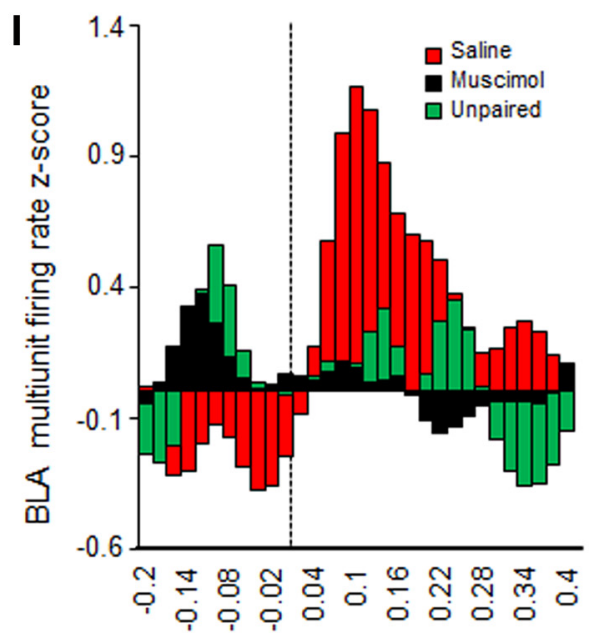

time (s)

Figure 7. Local activity in Te2 is necessary for CS-evoked activity in the BLA and for remote threat memory retrieval.A, Example of fluorescent muscimol diffusion in Te2.Scale bar, $500 \mu \mathrm{m} . \boldsymbol{B}-\boldsymbol{D}$, Percentage freezing during remote memory recall in an unpaired group $(n=7)$ and in fear conditioned rats that received injections of saline $(n=11)$ or the GABA-A receptor agonist muscimol $(n=11)$ in the Te2. $E$, Input- output auditory curves showing the average startle amplitudes (arbitrary units) at different auditory stimulus intensities (dB) measured the day before (DAY 1) and the day after muscimol or saline (DAY 2) injections. F, G,Administration of muscimol into the Te2 $1 \mathrm{~h}$ before remote memory recall impaired memory retention of white noises (WN) CSS. G, All data are mean \pm SEM. $\boldsymbol{H}$, Example traces of BLA responses in conditioned animals that received saline (top) or muscimol (middle) administration and the unpaired group (bottom). $I, Z$-scored population peristimulus time histograms in the three groups. BLA MUA in conditioned rats was statistically different from unpaired and muscimol-injected rats, whereas the latter two groups did not differ from each other.

tion, CS-evoked BLA firing did not differ from that of unpaired rats.

\section{Discussion}

Here we investigated the dynamic interaction between BLA and $\mathrm{Te} 2$ during the course of recent and remote memory retrieval. To this end, we performed simultaneous recordings of LFPs and MUA in both sites $24 \mathrm{~h}$ and 1 month after auditory fear conditioning. Although animals displayed conditioned freezing at both time points and both structures showed learning-evoked changes, BLA and Te2 interacted significantly only at the remote time interval. At late recall, $\mathrm{Te} 2$ entrained theta oscillations and neural firing in the BLA and the percentage of time that the Te2 led the BLA predicted the animals' ability to recognize auditory stimuli as aversive. This interplay is strictly related to the initial phase of memory retrieval because it is not present once the CS has been retrieved as an aversive stimulus. Finally, in the absence of this connectivity, BLA did not display any CS-related activity and was unable to support memory retention. We concluded that Te2-to-BLA information transfer serves to selectively retrieve the 
association between auditory stimuli and their learned emotion$\mathrm{al} /$ motivational consequences and that BLA contribution to remote emotional memories processing is due to its functional connectivity with sensory cortices.

\section{Time-dependent changes in the neural circuits mediating fearful memory retrieval}

During the retrieval of recent threat memories, both BLA and Te2 displayed learning-evoked changes in LFP power. Concerning BLA, the data are in line with previous findings showing that BLA activity changed $24 \mathrm{~h}$ after learned fear (Quirk et al., 1995; Rogan et al., 1997; Schafe et al., 2005) and that BLA low-theta activity increases following fear conditioning (Seidenbecher et al., 2003; Narayanan et al., 2007; Popa et al., 2010). Concerning the auditory cortex, its participation in the early stages of fear memory processing is poorly understood (Grosso et al., 2015a). Several studies showed that the activity of the auditory cortex is changed shortly after learning (Quirk et al., 1995; Weinberger, 2004, 2011; Peter et al., 2012; Weible et al., 2014). Moreover, fear conditioning to a complex auditory CS required the auditory cortex during training (Letzkus et al., 2011; Peter et al., 2012; Weible et al., 2014). On the other hand, our previous study reported that lesions of $\mathrm{Te} 2$ did not affect recent memory retrieval of simple auditory CSs (Sacco and Sacchetti, 2010). More recently, however, we reported that inactivation of $\mathrm{Te} 224 \mathrm{~h}$ after training impaired remote but not recent fear memories of simple auditory CSs (Grosso et al., 2015b). Based on the present findings, we suggest that the Te2 is involved, although not necessary, in the early processing of learned emotionally charged stimuli. Hence, early after training, there should be other pathway(s) that can support recent memory retention independently of the sensory cortex. In keeping with this idea, there was no evidence of any significant interplay between $\mathrm{Te} 2$ and BLA at this early time point. Possible candidate circuits for this behavior include thalamic afferents to BLA, which several studies have shown to be essential for recent fear memory retention (LeDoux, 2000; Tamietto and de Gelder, 2010; Weinberger, 2011) and also the cerebellar cortex, which is involved in threat memory (Sacchetti et al., 2002, 2004; Scelfo et al., 2008) through an interaction with BLA (Zhu et al., 2011). Conversely, during the recall of remote fearful memories, the neuronal activity of BLA and Te2 becomes highly synchronized in the theta frequency range. This synchrony is not due to the freezing response or auditory stimuli perception and processing, being all factors similarly present during recent and remote memory retrieval. Thus, it represents a functional connectivity, likely stemming from long-term memory consolidation processes. These data support the view that fear memories undergo a prolonged consolidation process that strongly rewires the neural circuits mediating memory storage and retrieval (Sacco and Sacchetti, 2010; Do-Monte et al., 2015). Furthermore, these findings provide strong evidence that the consolidation process leads to a preponderant Te2-to-BLA directionality during memory recall (i.e., it endows the sensory neocortex with the ability to drive subcortical nuclei, like the amygdala, during learned affective stimulus retrieval). In other words, these data suggest that BLA participation in remote threat memories is dependent on information stored in the cortex and that other information, if any, encoded at the subcortical-to-BLA pathway are not sufficient per se to activate BLA neurons in the presence of learned threatening signals. This result is at odds with the overarching "standard hypothesis" that sensory inputs to the amygdala come from both the thalamus and the sensory neocortex (LeDoux, 2000; Tamietto and de Gelder, 2010) and that fear conditioning to a simple auditory CS can be mediated by either of these pathways (LeDoux, 2000; Tamietto and de Gelder, 2010). Such a subcortical connectivity may be essential for recently formed threat memories, a time interval in which Te2 and BLA did not show a significant synchrony, but it cannot permanently support affective memories per se (Pessoa and Adolphs, 2010).

\section{Te2-to-BLA connectivity plays an essential role in the retrieval of the learned CS-US association}

The other important aspect of this work is related to the behavioral function of Te2-to-BLA connectivity. We found that the percentage of time that the Te2 led the BLA correlated with a faster latency to freeze to the CS. These data suggested that information encoded in the Te 2 through its connections to the BLA serves to selectively retrieve the association between sensory stimuli and their emotional/motivational consequences. Alternatively, it may also be that such a connectivity serves to recognize salient CSs independently of their valence. However, a recent study showed that $\mathrm{Te} 2$ is necessary for the encoding of the valence rather than the salience of auditory CSs (Grosso et al., 2015b). In keeping with our interpretation, previous studies have shown that in monkeys the neuronal firing of auditory cortex provides a representation of reward feedback by reflecting both the reward expectancy and the reward-size received (Brosch et al., 2011). Furthermore, Te2 activity patterns predict behavioral responses in a conditioned task (Villa et al., 1999). Moreover, changes in the neuronal activity of auditory cortical neurons predicted behavioral performance (Jaramillo and Zador, 2011) and convey signals to the striatum that drive behavioral choices during an auditory discrimination task (Znamenskiy and Zador, 2013). In humans, the blood oxygen level-dependent signal to learned frightening stimuli persists in the auditory association cortex throughout all sessions, as "a way to keep the possible threat of this stimulus highlighted” (Apergis-Schoute et al., 2014).

Intriguingly, Repa et al. (2001) reported that during fear conditioning there are neurons in the dorsal portion of the lateral amygdale, which changed their firing rapidly but only transiently, whereas in the ventral part of the lateral amygdala cells had longer latency responses but maintained enhanced responding throughout training and even through extinction. The authors proposed that the latter type of neurons is involved in the storage of fear memories (Repa et al., 2001). Given that our recordings were mostly done from the ventral part of the lateral amygdala, Te2to-BLA connectivity may refer to such amygdalar neurons involved in the storage of fear memories. Remarkably, we also found that, in the absence of such cortical information, BLA neurons were unable to distinguish between frightening and neutral cues. Hence, BLA contributions to the retrieval of learned affective significance of sensory stimuli depend on their functional connectivity with higher-order sensory cortices. Conversely, we did not find any correlations between the percentage of Te2-toBLA leading and the overall strength of the expressed fear behavior. Thus, this functional interplay does not serve to regulate fear expression toward sensory cues. Indeed, the regulation of fear behaviors to both innate and learned stimuli requires the prefrontal cortex (Courtin et al., 2014; Herry and Johansen, 2014) and its connections to BLA (Adhikari et al., 2011; Likhtik et al., 2014; Do-Monte et al., 2015; Likhtik and Paz, 2015). The amygdala may therefore represent the receipt of different information that is stored over time in distinct cortical sites, such as prefrontal and sensory areas, which play complementary but different functions. 


\section{References}

Adhikari A, Sigurdsson T, Topiwala MA, Gordon JA (2010) Crosscorrelation of instantaneous amplitudes of field potential oscillations: a straightforward method to estimate the directionality and lag between brain areas. J Neurosci Methods 191:191-200. CrossRef Medline

Adhikari A, Topiwala MA, Gordon JA (2011) Single units in the medial prefrontal cortex with anxiety-related firing patterns are preferentially influenced by ventral hippocampal activity. Neuron 71:898-910. Medline

Apergis-Schoute AM, Schiller D, LeDoux JE, Phelps EA (2014) Extinction resistant changes in the human auditory association cortex following threat learning. Neurobiol Learn Mem 113:109-114. CrossRef Medline

Barbieri F, Mazzoni A, Logothetis NK, Panzeri S, Brunel N (2014) Stimulus dependence of local field potential spectra: experiment versus theory. J Neurosci 34:14589-14605. CrossRef Medline

Berens P (2009) CircStat: a MATLAB Toolbox for Circular Statistics. J Statistical Software 31 (http://www.jstatsoft.org/v31/i10).

Brosch M, Selezneva E, Scheich H (2011) Representation of reward feedback in primate auditory cortex. Front Syst Neurosci 5:5. CrossRef Medline

Buzsáki G (2002) Theta oscillations in the hippocampus. Neuron 33:25-40. CrossRef Medline

Buzsáki G (2006) Rhythms of the brain. New York: Oxford UP.

Buzsáki G, Anastassiou CA, Koch C (2012) The origin of extracellular fields and currents EEG, ECoG, LFP and spikes. Nat Rev Neurosci 13:407-420. CrossRef Medline

Courtin J, Chaudun F, Rozeske RR, Karalis N, Gonzalez-Campo C, Wurtz H, Abdi A, Baufreton J, Bienvenu TC, Herry C (2014) Prefrontal parvalbumin interneurons shape neuronal activity to drive fear expression. Nature 505:92-96. CrossRef Medline

Do-Monte FH, Quiñones-Laracuente K, Quirk GJ (2015) A temporal shift in the circuits mediating retrieval of fear memory. Nature 519:460-463. CrossRef Medline

Gale GD, Anagnostaras SG, Godsil BP, Mitchell S, Nozawa T, Sage JR, Wiltgen B, Fanselow MS (2004) Role of the basolateral amygdala in the storage of fear memories across the adult lifetime of rats. J Neurosci 24: 3810-3815. CrossRef Medline

Gewirtz JC, Davis M (2000) Using pavlovian higher-order conditioning paradigms to investigate the neural substrates of emotional learning and memory. Learn Mem 7:257-266. CrossRef Medline

Grosso A, Cambiaghi M, Concina G, Sacco T, Sacchetti B (2015a) Auditory cortex involvement in emotional learning and memory. Neuroscience 299:45-55. CrossRef Medline

Grosso A, Cambiaghi M, Renna A, Milano L, Merlo G, Sacco T, Sacchetti B (2015b) The higher-order auditory cortex is involved in the assignment of affective value to sensory stimuli. Nat Comm. Advance online publication. Retrieved Dec. 1, 2015. doi: 10.1038/ncomms9886. CrossRef Medline

Herry C, Johansen JP (2014) Encoding of fear learning and memory in distributed neuronal circuits. Nat Neurosci 17:1644-1654. CrossRef Medline

Jaramillo S, Zador AM (2011) The auditory cortex mediates the perceptual effects of acoustic temporal expectation. Nat Neurosci 14:246-251. CrossRef Medline

Kim JJ, Fanselow MS (1992) Modality-specific retrograde amnesia of fear. Science 256:675-677. CrossRef Medline

Kolb B, Tees RC (1990) The cerebral cortex of the rat, pp 99-101, 381-392. Cambridge, MA: Massachusetts Institute of Technology.

Lapish CC, Chiang J, Wang JZ, Phillips AG (2012) Oscillatory power and synchrony in the rat forebrain are altered by a sensitizing regime of d-amphetamine. Neuroscience 203:108-121. CrossRef Medline

LeDoux JE (2000) Emotion circuits in the brain. Annu Rev Neurosci 23: 155-184. CrossRef Medline

Letzkus JJ, Wolff SB, Meyer EM, Tovote P, Courtin J, Herry C, Lüthi A (2011) A disinhibitory microcircuit for associative fear learning in the auditory cortex. Nature 480:331-335. CrossRef Medline

Likhtik E, Paz R (2015) Amygdala-prefrontal interactions in (mal)adaptive learning. Trends Neurosci 38:158-166. CrossRef Medline

Likhtik E, Stujenske JM, Topiwala MA, Harris AZ, Gordon JA (2014) Prefrontal entrainment of amygdala activity signals safety in learned fear and innate anxiety. Nat Neurosci 17:106-113. CrossRef Medline

Martin JH, Ghez C (1999) Pharmacological inactivation in the analysis of the central control of movement. J Neurosci Methods 86:145-159. CrossRef Medline

McDonald AJ, Jackson TR (1987) Amygdaloid connections with posterior insular and temporal cortical areas in the rat. J Comp Neurol 262:59-77. CrossRef Medline

McGaugh JL (2015) Consolidating memories. Annu Rev Psychol 66:1-24. CrossRef Medline

Miserendino MJ, Sananes CB, Melia KR, Davis M (1990) Blocking of acquisition but not expression of conditioned fear-potentiated startle by NMDA antagonists in the amygdala. Nature 345:716-718. CrossRef Medline

Nácher V, Ledberg A, Deco G, Romo R (2013) Coherent $\delta$-band oscillations between cortical areas correlate with decision making. Proc Natl Acad Sci U S A 110:15085-15090. CrossRef Medline

Narayanan RT, Seidenbecher T, Kluge C, Bergado J, Stork O, Pape HC (2007) Dissociated theta phase synchronization in amygdalo-hippocampal circuits during various stages of fear memory. Eur J Neurosci 25:1823-1831. CrossRef Medline

Oostenveld R, Fries P, Maris E, Schoffelen JM (2011) FieldTrip: open source software for advanced analysis of MEG, EEG, and invasive electrophysiological data. Comput Intell Neurosci 2011:156869. CrossRef Medline

Paxinos G, Watson C (1986) The rat brain in stereotaxic coordinates. San Diego: Academic.

Pessoa L, Adolphs R (2010) Emotion processing and the amygdala: from a 'low road' to 'many roads' of evaluating biological significance. Nat Rev Neurosci 11:773-783. CrossRef Medline

Peter M, Scheuch H, Burkard TR, Tinter J, Wernle T, Rumpel S (2012) Induction of immediate early genes in the mouse auditory cortex after auditory cued fear conditioning to complex sounds. Genes Brain Behav 11:314-324. CrossRef Medline

Popa D, Duvarci S, Popescu AT, Léna C, Paré D (2010) Coherent amygdalocortical theta promotes fear memory consolidation during paradoxical sleep. Proc Natl Acad Sci U S A 109:14416-14421. CrossRef Medline

Quirk GJ, Repa C, LeDoux JE (1995) Fear conditioning enhances shortlatency auditory responses of lateral amygdala neurons: parallel recordings in the freely behaving rat. Neuron 15:1029-1039. CrossRef Medline

Repa JC, Muller J, Apergis J, Desrochers TM, Zhou Y, LeDoux JE (2001) Two different lateral amygdala cell populations contribute to the initiation and storage of memory. Nat Neurosci 4:724-731. CrossRef Medline

Rogan MT, Stäubli UV, LeDoux JE (1997) Fear conditioning induces associative long-term potentiation in the amygdala. Nature 390:604-607. CrossRef Medline

Romanski LM, LeDoux JE (1993) Information cascade from primary auditory cortex to the amygdala: corticocortical and corticoamygdaloid projections of temporal cortex in the rat. Cereb Cortex 3:515-532. CrossRef Medline

Sacchetti B, Lorenzini CA, Baldi E, Tassoni G, Bucherelli C (1999) Auditory thalamus, dorsal hippocampus, basolateral amygdala, and perirhinal cortex role in the consolidation of conditioned freezing to context and to acoustic conditioned stimulus in the rat. J Neurosci 19:9570-9578. Medline

Sacchetti B, Baldi E, Lorenzini CA, Bucherelli C (2002) Cerebellar role in fearconditioning consolidation. Proc Natl Acad Sci U S A 11:8406-8411. CrossRef Medline

Sacchetti B, Scelfo B, Tempia F, Strata P (2004) Long-term synaptic changes induced in the cerebellar cortex by fear conditioning. Neuron 42: 973-982. CrossRef Medline

Sacco T, Sacchetti B (2010) Role of secondary sensory cortices in emotional memory storage and retrieval in rats. Science 6:649-656. Medline

Scelfo B, Sacchetti B, Strata P (2008) Learning-related long-term potentiation of inhibitory synapses in the cerebellar cortex. Proc Natl Acad Sci U S A 105:769-774. CrossRef Medline

Schafe GE, Doyère V, LeDoux JE (2005) Tracking the fear engram: the lateral amygdala is an essential locus of fear memory storage. J Neurosci 25:10010-10014. CrossRef Medline

Schafe GE, LeDoux JE (2000) Memory consolidation of auditory pavlovian fear conditioning requires protein synthesis and protein kinase $\mathrm{A}$ in the amygdala. J Neurosci 20:RC96. Medline

Seidenbecher T, Laxmi TR, Stork O, Pape HC (2003) Amygdalar and hippocampal theta rhythm synchronization during fear memory retrieval. Science 301:846-850. CrossRef Medline 
Tamietto M, de Gelder B (2010) Neural bases of the non-conscious perception of emotional signals. Nat Rev Neurosci 11:697-709. CrossRef Medline

Valsamis B, Schmid S (2011) Habituation and prepulse inhibition of acoustic startle in rodents. J Vis Exp 55:e3446. CrossRef Medline

Villa AE, Tetko IV, Hyland B, Najem A (1999) Spatiotemporal activity patterns of rat cortical neurons predict responses in a conditioned task. Proc Natl Acad Sci U S A 96:1106-1111. CrossRef Medline

Weible AP, Liu C, Niell CM, Wehr M (2014) Auditory cortex is required for fear potentiation of gap detection. J Neurosci 34:15437-15445. CrossRef Medline

Weinberger NM (2004) Specific long-term memory traces in primary auditory cortex. Nat Rev Neurosci 5:279-290. CrossRef Medline

Weinberger NM (2011) The medial geniculate, not the amygdala, as the root of auditory fear conditioning. Hear Res 274:61-74. CrossRef Medline

Wilensky AE, Schafe GE, LeDoux JE (1999) Functional inactivation of the amygdala before but not after auditory fear conditioning prevents memory formation. J Neurosci 19:RC48. Medline

Zhu L, Sacco T, Strata P, Sacchetti B (2011) Basolateral amygdala inactivation impairs learning-induced long-term potentiation in the cerebellar cortex. PLoS One 6:e16673. CrossRef Medline

Zilles K (1985) The cortex of the rat: a stereotaxic atlas. Berlin: Springer-Verlag.

Znamenskiy P, Zador AM (2013) Corticostriatal neurons in auditory cortex drive decisions during auditory discrimination. Nature 497:482-485. CrossRef Medline 